\title{
A GÊNESE SOCIAL DAS POLÍTICAS PÚBLICAS TERRITORIAIS BRASILEIRAS: AS DEMANDAS DOS MOVIMENTOS DOS SEM TERRA E SEU PROCESSO DE INSTITUCIONALIZAÇÃO
}

\author{
The Social Genesis of Brazilian Territorial Public Policies: The Demands of Land \\ Movements and its Institutionalization Process
}

\begin{abstract}
RESUMO
O debate sobre a questão agrária, basicamente, remete a interpretações sobre o desenvolvimento capitalista na esfera rural. Inicia-se no século XIX e ganha aderência e repercussão política a partir da primeira metade do século XX. Neste sentido, muitas problemáticas que envolvem a questão agrária necessariamente estão relacionadas: 1) ao monopólio da propriedade fundiária; 2) às relações desiguais entre latifundiários e camponeses e; 3) aos conflitos oriundos da luta pela terra. É seguindo estas pistas que este paper visa demonstrar que as construções por espaços de participação servem mais para abrandar possíveis conflitos do que para solucionar a questão da luta pela terra, que divide trabalhadores rurais versus latifundiários. O estudo de caráter exploratório considera a realização de pesquisas bibliográfica e documental e nos permite inferir que, durante a gestão dos governos petistas (2002 a 2015), os movimentos sociais, em especial, o movimento dos sem-terra (MST) passaram a ressignificar suas formas de atuação, deslocando-se a um estágio de concertação e consenso, em relação à tecnocracia governamental, principalmente, na relação com o Ministério de Desenvolvimento Agrário - hoje fundido na pasta ministerial de Desenvolvimento Social -, o que traz, como consequência direta, o fortalecimento por outro lado das pautas do agronegócio brasileiro, que, representada pelo Ministério da Agricultura, adquire a cada ano mais espaço e importância na agenda governamental brasileira.
\end{abstract}

William Dos Santos Melo

Fundação Getúlio Vargas

william_santos_melo@yahoo.com.br

Pedro Gomes Andrade

Universidade de Estadual Campinas

pedrogandrade@yahoo.com.br

Paula Lemos Azem

Pontifícia Universidade Católica

pazem@globo.com

Recebido em: 14/07/2016. Aprovado em: 16/07/2018.

Avaliado pelo sistema double blind review

Avaliador científico: Renato Silvério Campos

DOI: 10.21714/2238-68902018v20n1p049

\begin{abstract}
The debate on the agrarian question necessarily refer to interpretations of capitalist development in the rural sphere. This debate begins in the nineteenth century and gained grip and political repercussions from the first half of the twentieth century. In this sense, many of the issues that involve the land question are necessarily related: 1) the monopoly of land ownership; 2) the unequal relations between landowners and peasants; 3) conflicts arising from the struggle for land. By following these clues that this paper object to demonstrate that the buildings with spaces for participation do more to mitigate possible conflicts than to resolve the question of the struggle for land that divides peasants contrary to landlords. The study, exploratory, has the realization of bibliographic and documentary research and allows us to infer that during the management of PT governments (2002-2015), social movements, particularly the landless movement (MST) began to reframe their ways of working, going to a concert stage and consensus with government technocracy, particularly in relation to the Ministry of Agrarian Development - now cast in the ministerial portfolio of Social Development -, which has as a direct consequence of the strengthening on the other hand the tactics of brazilian agribusiness, which represented the Ministry of Agriculture acquires every year more space and importance in the government strategy.
\end{abstract}

Palavras-Chave: Latifundiários, Trabalhadores Rurais, Estado, Conflito, Participação.

Keywords: Landowners, Rural Workers, State, Conflict, Participation. 


\section{INTRODUÇÃO}

Este trabalho tem a intenção de debater e refletir alguns pressupostos correlacionados à questão agrária brasileira, como seus atores e as atuais políticas públicas adotadas pelo Estado. Sendo assim, os escritos aqui realizados visam contribuir para estudos que conjuguem análises tanto dos movimentos sociais, presentes na esfera rural, quanto também das ações estatais estabelecidas nos últimos anos. Ao adotar esta postura de investigação científica, há a demonstração por parte destes autores da crença de que o processo de mudanças existentes tanto pelos movimentos sociais, quanto no que se refere ao crescimento e adoção das políticas públicas territoriais, são intrinsecamente antitéticas (unidades dos contrários). Ou seja, os movimentos sociais começam a se organizar e pressionar o governo e latifundiários, que, por sua vez, estabelecem novas composições, políticas ou repressivas, o que fundamentalmente leva os movimentos sociais a voltarem a realizar novos movimentos e uma nova agenda de interesses, num ininterrupto ciclo, cujo conflito sempre é a mola propulsora.

Seguindo a trajetória interpretativa exposta acima, o trabalho pretende, assim, estabelecer como hipótese que a adoção das atuais políticas territoriais, além de ser resposta às demandas de movimentos sociais, serve, também, como instrumento de mediação para minimizar os conflitos decorrentes das relações entre trabalhadores sem-terra - neste caso, o Movimento dos Trabalhadores Rurais Sem-Terra (MST), já que este movimento é o mais organizado e ativo no que se refere à luta em prol das demandas dos trabalhadores rurais - e grandes proprietários - latifundiários e representantes do agronegócio levando os movimentos sociais, a partir de canais de participação, a se institucionalizarem e dissuadirem-se pelo argumento do consenso, dos financiamentos e da possibilidade de assentamentos.

$\mathrm{Na}$ finalidade de ressaltar os objetivos aqui já expostos, o trabalho abordará o intenso debate e interpretações sobre a questão agrária brasileira, refletindo sobre nossa formação social, acrescentada de contemporâneas interpretações sobre o assunto. Posteriormente, será exposto, de forma sucinta, todo o processo de formação de um dos maiores movimentos sociais brasileiros: o Movimento dos Trabalhadores Rurais Sem-Terra e, por fim; será analisado o desenho das atuais políticas territoriais brasileiras e como elas acabam levando à institucionalização dos movimentos sociais e à exaltação da política de consenso entre Estado, trabalhadores rurais e empresários do agronegócio ${ }^{1}$.

\section{A QUESTÃO AGRÁRIA BRASILEIRA}

O debate sobre a questão agrária, basicamente, remete a interpretações sobre o desenvolvimento capitalista na esfera rural. Inicia-se no século XIX e ganha mais aderência e repercussão política a partir da primeira metade do século XX. Neste sentido, muitas problemáticas que envolvem a questão agrária, necessariamente, estão relacionadas: 1) ao monopólio da propriedade fundiária; 2) às relações desiguais entre latifundiários e camponeses, tais como a precarização na relação de trabalho (camponeses versus latifundiários) e do aumento da pobreza e; 3 ) aos conflitos oriundos da luta pela terra.

Ao remontar a gênese destas questões acima apresentadas, constata-se, utilizando-se da pista deixada por Martins (1986), que ela advém de nossa formação social, principalmente, a partir da abolição da escravatura, que deu lugar ao trabalho livre, sem que estes homens e mulheres fossem inseridos social e economicamente na sociedade brasileira. Neste contexto, nossa formação agrária se realizou, a partir da necessidade por parte dos novos trabalhadores livres (escravos) em manterem sua subsistência e sobrevivência, vendendo, por sua vez, sua força de trabalho por qualquer "vintém", enquanto os grandes proprietários, diante da abundância de terras e de sua força política e militar, transformavam um exército de escravos agora em um exército de desvalidos assalariados. Com esta conformação, os escravos, agora transformados em trabalhadores do campo, ficavam imersos num círculo vicioso que se resumia em trabalhar, sobreviver e se manter preso - por dívidas, falta de opções ou medo - ao trabalho da terra de seu patrão, que, outrora, aumentava seus ganhos e tornava seu empregado cada vez mais refém de seus mandos e de suas vontades. Neste sentido, quem

\footnotetext{
${ }^{1}$ Logicamente que, após a ascensão do vice-presidente Michel Temer, a presidência do país - pelo afastamento da então presidenta Dilma Rousseff, no processo de impeachment - parte da agenda relacionada ao desenvolvimento territorial encontra-se em suspensão. Uma perda considerável já pode ser percebida, que é a fragmentação do então Ministério do Desenvolvimento Agrário (criado no idos do governo FHC) ter sido fundida à pasta ministerial de Desenvolvimento Social. A redução das pastas ministeriais, com a justificativa de corte de gastos, acertou, estrategicamente, as pautas da agricultura familiar, dando ainda mais protagonismo ao agronegócio. Tais ações podem revigorar os movimentos de combate e recolocar o Movimento dos Trabalhadores Rurais Sem-Terra (MST) no rumo de suas pautas tradicionais, revigorando-a em uma instituição crítica e de oposição ao governo.
} 
não tinha terra passava a trabalhar para os fazendeiros que enriqueciam e mantinham seu poder e prestígio em suas localidades.

Apenas nos anos cinquenta, esta realidade será alterada e passará a ser colocada em termos sociais. Isto se dá, porque, nestes anos, a agricultura brasileira se moderniza tecnologicamente. Neste momento, uma boa parcela dos trabalhadores rurais é expulsa de seus locais de trabalho e esta expulsão ocorre pela falta de adaptação às novas formas de produção agropecuária, como também à diminuição da necessidade de os grandes proprietários da quantidade de trabalhadores braçais, enfraquecendo, consequentemente, o trabalho intensivo no campo e aumentando, por sua vez, o trabalho sazonal.

Em decorrência do aumento do trabalho sazonal, iniciam-se as primeiras migrações temporárias em busca de ocupação. Este processo evidencia o nascimento da figura do trabalhador sem-terra, ou seja, um trabalhador em busca de condições de sobrevivência (de terra ou trabalho). $\mathrm{O}$ descaso perante o aumento no contingente de trabalhadores nesta situação leva a questão agrária a apresentar, daí para frente, um intenso problema social, tanto no sentido da incapacidade de o Estado em criar mecanismos de inclusão destes trabalhadores, como também a de evitar os primeiros confrontos entre latifundiários e trabalhadores rurais, que residem basicamente em uma questão: A reforma agrária (NAVARRO, 2001).

Neste momento, fica explícito o novo conflito que passará a nortear os debates e ações referentes à questão agrária brasileira, sendo defendido, ideologicamente, por duas visões de mundo. De um lado, os trabalhadores rurais (que, ao longo dos anos, conformarão o Movimento dos Trabalhadores Rurais Sem- Terra (MST), as pastorais sociais e demais movimentos sociais organizados do campo) que apostam num projeto que possa interferir, profundamente, no direito da propriedade instituído, ainda em 1850, pela Lei de Terras ${ }^{2}$ e fortalecido com a Lei do Estatuto da Terra ${ }^{3}$, em 1964 (instituído no regime militar), criando meios de desapropriação/confisco do latifúndio para redistribuição gratuita aos sem-terra. De outro lado, a comunhão do Estado com representantes dos latifundiários, levando-os a institucionalizar as demandas dos trabalhadores rurais e pontualmente formatando o

${ }^{2}$ Lei $\mathrm{n}^{\circ}$ 601, de 18 de setembro de 1850, disponível em:<http://www. planalto.gov.br/ccivil_03/LEIS/L0601-1850.htm>.

${ }^{3}$ Lei $n^{\circ} 4.504$, de 30 de novembro de 1964, disponível em: <http://www. planalto.gov.br/ccivil_03/Leis/L4504.htm>. debate sobre a reforma agrária, a partir de assentamentos e demais políticas sociais setoriais (SAMPAIO, 2003).

Já no que refere a uma interpretação mais recente da questão agrária brasileira, Fernandes (2004) aproximando-se da mesma linha interpretativa exposta acima - compreende que há duas linhas ideológicas e propositivas, que denomina como paradigmáticas, sendo a primeira de inspiração kautskyana e a segunda de inspiração comparativista.

No que se refere à abordagem kautskyana, dominavam os debates teóricos e propositivos da questão agrária brasileira até o final da década de 80 . Conforme Oliveira (1991) demonstra, este grupo centrava-se em compreender as modificações sofridas pelos camponeses, por meio da diferenciação interna, produzida pelas contradições típicas do processo de integração no mercado capitalista ou pelo processo de "penetração das relações capitalistas de produção no campo" (OLIVEIRA, 1991, p. 45). Ao se debruçarem sobre esses processos, eles buscavam compreender a proletarização do campesinato. Já, em outra vertente - como é o caso de Martins (1986), aqui já citado - compreendiam ainda que o campesinato em si é dinâmico, sendo criado, destruído e recriado pelo próprio desenvolvimento contraditório do capitalismo. Sendo assim, essa vertente teórica tinha/ tem como principais elementos de análise da questão agrária, três pressupostos principais: 1) a renda da terra; 2) a diferenciação econômica do campesinato e; 3) as desigualdades sociais geradas pelo desenvolvimento do capitalismo na esfera rural ${ }^{4}$.

Já, na década de 90, ganha força a interpretação comparativista, inspirada nos estudos de Abramovay, sendo a obra: "Paradigmas do Capitalismo Agrário em Questão", referência expressiva da nova da ótica sobre a questão agrária brasileira. Nesta obra, Abramovay rompe com o paradigma marxista ou kautskyano e apresenta, por sua vez, uma leitura do desenvolvimento da agricultura, nos países capitalistas ricos, demonstrando que estes países passavam necessariamente por estágios pré-determinados de desenvolvimento, salientando que a agricultura de base familiar era um fator decisivo para a consolidação de um desenvolvimento capitalista vigoroso e necessário para sanar questões sociais na esfera rural. Suas considerações sobre o tema logo se tornam referências importantes, passando a inspirar o governo, que intensifica políticas públicas, para a esfera rural brasileira, a partir, especificamente:

${ }^{4}$ Sobre o tema ver: STĖDILE, J. P. A questão agrária hoje. Porto Alegre: UFRGS, 1994. 
1) da exaltação à agricultura familiar; 2) da necessidade de assentamentos rurais e; 3) do atendimento pontual de demandas das minorias sociais: mulheres, populações tradicionais e etc (OLIVEIRA, 2003).

No desiderato de todas estas variáveis, presentes na questão agrária brasileira, percebe-se que o conflito segue permeando todos os acontecimentos. A discussão sobre reforma agrária brasileira não avança e o governo, a fim de remediar os males existentes na esfera rural brasileira, pressionada por interesses dos latifundiários - agora denominados de agribusiness - segue adotando políticas públicas de desenvolvimento territorial focadas em assentamentos e em desenvolver a agricultura familiar, utilizando de casos bem sucedidos na Europa ${ }^{5}$. Movimento dos Trabalhadores Rurais Sem-Terra (MST), outrora importante movimento impulsionador da agenda política para a esfera rural, parece padecer de um forte processo de institucionalização, principalmente, a partir da gestão do ex-presidente Luís Inácio Lula da Silva, enfraquecendo, assim, o movimento e novas possíveis conquistas. Os governos petistas, de forma geral, estabelecem o discurso da conciliação de interesses e, neste sentido, emudecem os movimentos sociais e tranquiliza os grandes latifundiários, nos últimos 10 anos.

The state tolerance form on-violent confrontation is a challenge. On the one hand, provides ways relatively risk gathering a large number of people and gives them the feeling of being significantly acting on behalf of their beliefs. On the other hand, takes the social movements a powerful weapon: the indignation. It is easier to mobilize themselves against police [or state] violent eccentric and shooting young insurgents[and landless peasants] and sincere in jail than against public officials who seem sensible and organizing seminars for participants[...] protect $[i n g]$ their freedom of expression against opponents (DELLA PORTA et al, 1997, p. 102, grifos do autor $)^{6}$.

${ }^{5}$ Sobre o tema ver: BEDUSCHI FILHO, L. C.; ABRAMOVAY, R. Desafio para o desenvolvimento das regiões rurais. Nova Economia. Belo Horizonte, v. 14, n. 3, p. 35-70. set-dez. 2004. ORTEGA, A. C.; MENDONÇA, N. C Estratégias de desenvolvimento rural no Brasil: continuidades e rupturas. In: ALMEIDA FILHO, N. (Org.). Desenvolvimento territorial: Segurança Alimentar e economia solidária. Campinas: Alínea, 2007.

${ }^{6}$ Tradução livre do autor:"A tolerância do Estado, em relação ao confronto não violento, é uma faca de dois gumes. De um lado, proporciona maneiras relativamente sem risco de reunir um grande número de pessoas e dar-lhes a sensação de estarem agindo, significativamente, em benefício de suas crenças. Por outro lado, tira dos movimentos sociais uma arma poderosa: a indignação. É mais fácil mobilizar-se contra uma polícia [ou um Estado] violenta[o] e excêntrica[o] que atira insurgentes jovens [e trabalhadores sem-terra] e sinceros na cadeia do que contra autoridades públicas que parecem sensatas e que organizam seminários para os participantes [...] protege[ndo] sua liberdade de expressão contra opositores" (DELLA PORTA et al, 1997, p. 102, tradução livre e grifos do autor)

\section{UM BREVE HISTÓRICO DO MOVIMENTO DOS TRABALHADORES RURAIS SEM-TERRA}

Ao abordar a questão agrária no Brasil, torna-se sempre necessário relembrar e compreender as ações, demandas e origens dos trabalhadores rurais sem-terra, seja pela importância de suas reivindicações ou para compreender a temática por olhares mais afeitos aos trabalhadores em vez de abordagens que privilegiam a ótica do governo, ou mesmo da classe empresarial deste setor (IPEA, 2011).

Neste sentido, explicitar esta longa caminhada aqui se fará necessário, para que este trabalho possa alcançar um de seus principais objetivos: o de demonstrar que as demandas e pressões exercidas por este movimento social foram decisivas não apenas para a criação do Ministério do Desenvolvimento Agrário (MDA), em $2000^{7}$, mas também como fundamental para os desenhos contemporâneos de políticas territoriais no país (Programa Nacional de Agricultura Familiar - Pronaf; Programa Nacional de Desenvolvimento Sustentável dos Territórios Rurais - Pronat; Programa Territórios da Cidadania - PTC), como na próxima seção deste trabalho ficará evidenciado.

No que concerne ao movimento inicial dos trabalhadores rurais sem-terra ${ }^{8}$ (MST), de acordo com Frei Sergio e Stédile (1993), o movimento não possui uma data específica que defina seu nascimento. Sua origem combina várias iniciativas em várias localidades. Na verdade, sua história de formação como movimento social é composta pela soma de um conjunto de acontecimentos e fatores ocorridos a partir de 1978. Neste período, aconteceram, em vários estados, lutas de agricultores sem-terra que, de forma coletiva, buscavam a conquista de áreas cultiváveis. A forma de luta mais utilizada passou a ser a

${ }^{7} \mathrm{O}$ MDA foi regulamentado pelo Decreto $\mathrm{n}^{\circ} 3.338 / 2000$, a partir de um processo de evolução que se iniciou em 1982, com a criação do Ministério Extraordinário para Assuntos Fundiários (MEAF); posteriormente, em 1985, a partir do Ministério da Reforma e do Desenvolvimento Agrário (MIRAD); logo após, em 1989, com a extinção do MIRAD, suas demandas foram incorporadas ao Ministério da Agricultura; em 1996, foi criado o Ministério Extraordinário de Política Fundiária (MEPF); em 1999, foi transformado o MEPF em Ministério da Política Fundiária e Agricultura Familiar; e, definitivamente, em 2000, institucionalizado o Ministério do Desenvolvimento Agrário (MDA).

${ }^{8} \mathrm{O}$ termo "sem-terra", na verdade, é uma versão popular do conceito sociológico de camponeses que trabalham a terra sem serem proprietários dela. O sentido que este trabalho aborda, conjuntamente com demais análises, é o de camponês ou de trabalhadores camponeses, incluindo, assim, as lutas sociais e culturais de grupos que, na atualidade, ainda tentam garantir a sobrevivência deste trabalho. A noção inclui o conjunto de trabalhadores do campo - homens e mulheres -, inclusive, os remanescentes de quilombolas, as nações indígenas e os diversos tipos de assalariados vinculados à vida e ao trabalho no meio rural. 
das ocupações - dando início a uma série de confrontos entre trabalhadores rurais e proprietários de terra - em diferentes regiões do país, tais como Rio Grande do Sul; Santa Catarina; Mato Grosso; Paraná; Bahia; Rio de Janeiro e Goiás.

A partir da década de 1980, as lideranças dos variados grupos de ocupação de terra passam a manter encontros mais frequentes, sob a supervisão da Comissão Pastoral da Terra (CPT). Em 1984, amadurece-se este processo de articulação e organização, realizando-se assim o I Encontro Nacional dos Sem-Terra, em Cascavel, no Paraná. Este encontro significou a fundação de uma organização de camponeses sem-terra, em nível nacional, com o objetivo de lutar por terra e reforma agrária, nascendo, definitivamente, o Movimento dos Trabalhadores Rurais ${ }^{9}$ Sem-Terra (MST). Após o I Encontro Nacional, outros vieram para fortalecer ainda mais o movimento, em 1985, no Paraná e, em 1990, em Brasília.

Como já explicitado, um conjunto de fatores levou ao surgimento e organização do que passaria a ser um dos maiores movimentos sociais de luta no campo, o Movimento dos Trabalhadores Rurais Sem-Terra (MST). Entretanto é notório que a questão econômica definiuse como propulsora das principais reivindicações deste movimento. Esta se inicia, na década de 70, quando ocorre no país uma concentração de terras que pertencia a poucos proprietários e aprofunda-se o processo de mecanização da agricultura, com intensificação de insumos industriais. Neste período, muitas propriedades que se utilizavam de mão de obra, na forma de parceria ${ }^{10}$ e arrendamentos ${ }^{11}$, passam a descartar esses trabalhadores e substituí-los por máquinas. Os trabalhadores rurais são expulsos da terra, a monocultura da soja e do algodão para exportação acrescidos mais tarde da implantação do Pró-álcool

${ }^{9} \mathrm{~A}$ expressão "trabalhadores rurais", incluída no nome do movimento, visou caracterizar, desde o início, o fato de tratar-se de um movimento de agricultores, isto é, de pessoas que trabalham no meio rural e que estabelecem relações produtivas e afetivas com a terra.

${ }^{10}$ Parceiros são agricultores que trabalham com sua família, em forma de arrendamento para donos de terra. Normalmente, os proprietários de terra entram com a terra, às vezes, com a semente, adubos e etc. Na colheita, é feita a partilha da produção. Quando a divisão da produção ocorre de forma igualitária para cada um, estes passam a ser denominados de meeiros, mas tal fato dificilmente ocorre; geralmente os donos de terra ficam com a maior parte da produção, no mais, o pagamento sempre se dá apenas, a partir do produto colhido, não havendo envolvimento de dinheiro por parte de proprietários e trabalhadores rurais (STÉDILE et al, 1993).

${ }^{11}$ São agricultores que trabalham com sua família e arrendam uma área de suas terras por preço fixo, estes geralmente pagam pelo uso da terra em dinheiro ou com a parte da produção. O montante a ser pago não necessariamente depende do volume da colheita. Existem, também, os grandes arrendatários que contratam grandes extensões de terra, para cultivo de máquinas, estes são denominados de arrendatários capitalistas. (STÉDILE et al, 1993). contribuem ainda mais drasticamente, para um cenário caótico, os trabalhadores rurais, a partir deste momento, iniciam uma das fases mais complicadas em suas vidas, principalmente, no que se refere a oportunidades e direitos (STÉDILE, 2005a; 2005b).

Os fatores econômicos logo impactam a questão social, que passa a verificar um acentuado crescimento, no êxodo rural para a cidade e uma forte migração para a região Amazônica, decorrentes de um audacioso projeto de colonização nas fronteiras agrícolas ${ }^{12}$, que fracassa e leva milhares de trabalhadores rurais ao desemprego, tornando a situação ainda mais crítica. Neste mesmo período - como já apresentado - o trabalho pastoral da Igreja Católica, por meio da CPT e das pastorais sociais, passam a ser uma das únicas saídas, para milhares de trabalhadores rurais, que acabam tendo uma visão mais crítica de sua realidade e exigindo cada vez mais o direito a terra.

Acresce-se a esse fecundo movimento de conscientização, o surgimento do novo sindicalismo tendo como referência as grandes mobilizações e greves no $\mathrm{ABC}$ paulista - que passam a ter influência direta, inspirando o movimento dos trabalhadores rurais a uma organização de sindicalismo e que, posteriormente, ajuda o Movimento dos Trabalhadores Rurais Sem Terra (MST) em suas reivindicações por terras e demais demandas. No mais, o processo de abertura política e o esgotamento do regime militar contribuíram, também, para a organização definitiva do movimento, já que o medo da repressão política, via força policial e militar, conjunturalmente, estava perdendo forças.

No final da década de 80, o Movimento dos Trabalhadores Rurais Sem Terra (MST) tinha quadros bem organizados, o que os leva a consolidar o seu projeto de política agrícola para o país, tendo por parâmetro, de acordo com Balduíno (1999, p. 07), cinco fatores fundamentais:

1) Ocupação massiva de terras, envolvendo homens e mulheres, adultos e crianças, ou seja, a família inteira.

2) Novo modelo de produção associado à divisão do trabalho e renda, sem exploração dos trabalhadores, agregando as formas de trabalhos comunitários e cooperativados, bem como as técnicas e culturas de cada região.

3) Os assentamentos realizados em lugares bonitos, atraentes e com reflorestamento, tudo inspirado na

${ }^{12} \mathrm{O}$ marco histórico da ocupação da fronteira agrícola Amazônica se deu com mais pujança, a partir das instalações das rodovias na década de 1970: a Transamazônica, Cuiabá-Santarém e Cuiabá-Porto Velho. 
solidariedade, em que a alegria e a festa sempre devem estar presentes.

4) Uma abertura que rompa o isolamento, superando o sectarismo esquerdista, o dogmatismo intolerante e a rígida discriminação dos que podem ou não entrar no Movimento dos Trabalhadores Rurais Sem Terra (MST).

5) Além da reforma agrária, buscam-se mudanças imediatas e radicais das estruturas de iniquidade que geram o empobrecimento e a exclusão da maioria do povo brasileiro. [Neste sentido, o MST encarna uma espécie de missão, buscando representar os cidadãos brasileiros em busca de uma alternativa de um país como nação soberana] (BALDUÍNO, 1999, p. 07; grifos do autor).

Estes pressupostos tornam o Movimento dos Trabalhadores Rurais Sem Terra (MST) um movimento fortemente engajado que passa a se fazer cada vez mais presente no cenário nacional - por reportagens, estudos acadêmicos e pronunciamentos de intelectuais, clérigos e líderes do próprio movimento - esta nova fase do movimento leva-o a se tornar um instrumento de pressão ao governo e um incômodo aos anseios de latifundiários.

Para agravar ainda mais a situação de latifundiários e parte do governo, o Movimento dos Trabalhadores Rurais Sem Terra (MST) soma forças com a Confederação de Trabalhadores na Agricultura (CONTAG) que, por sua militância e por sua estrutura sindical formal, tornam o movimento ainda mais organizado, desencadeando, em 1995, o "Grito da Terra", uma enorme marcha nacional, em Brasília, que possibilitou aos trabalhadores rurais pressionarem o recém-eleito governo de Fernando Henrique Cardoso, que, em 1996, elabora o Pronaf - primeiro programa de desenvolvimento territorial depois da redemocratização - como resposta às demandas das lideranças dos movimentos dos trabalhadores rurais. Definitivamente, na década de 90, o Movimento dos Trabalhadores Rurais Sem Terra (MST) deixa de ser um movimento isolado, tornando-se, agora, um importante e novo ator no que se refere à questão agrária brasileira.

\section{A PARTICIPAÇÃO COMO FERRAMENTA DE INSTITUCIONALIZAÇÃO DO MOVIMENTO DOS TRABALHADORES RURAIS SEM TERRA}

Como esboçado na seção anterior, todo o processo agrário brasileiro é marcado por conflitos e por dificuldades por parte dos trabalhadores rurais pela conquista de direitos e oportunidades. Este cenário, no entanto começa a se alterar um pouco, a partir das pressões exercidas pelo MOVIMENTO DOS TRABALHADORES RURAIS SEM
TERRA e pelas criações de políticas de desenvolvimento territorial iniciada em meados da década de $90^{13}$.

A primeira ação, neste sentido, foi o Pronaf, criado como linha de crédito para agricultores familiares. O repasse de verbas era feito pelos municípios elegíveis, a partir da elaboração de planos de desenvolvimento rural, que eram aprovados pelos Conselhos Municipais de Desenvolvimento Rural (CMDRS). Nesse sentido, o CMDRS consubstanciava-se como umas das primeiras iniciativas de criação de espaços participativos entre o estado e a sociedade (ABRAMOVAY, 2001). A aposta por parte do governo, era o de acalmar os movimentos sociais do campo, a partir de esferas participativas, em que estes viessem a ter voz e pudessem colaborar para a política e o alcance de resultados, mesmo que, na prática, esta iniciativa não se confirmasse de maneira tão vigorosa.

As iniciativas, no que se refere à formação de canais de diálogos com os movimentos sociais rurais, persistem após os CMDRS e, no final da década de 90, é criado por decreto da presidência, no 3200, o Conselho Nacional de Desenvolvimento Rural (CNDR), integrante do Gabinete do Ministro de Estado Extraordinário de Política Fundiária, tendo por finalidade deliberar sobre o Plano Nacional de Desenvolvimento Rural (PNDR), que tinha por objetivo constituir diretrizes para os objetivos e metas do Programa Nacional de Reforma Agrária e do Pronaf. O órgão era constituído por membros do governo, em sua maioria e representantes da sociedade civil. Em 2000, o órgão colegiado passou a se chamar Conselho Nacional de Desenvolvimento Rural Sustentável (CNDRS), sendo integrante da estrutura regimental do então novo ministério - Ministério de Desenvolvimento Agrário (MDA), tendo por finalidade elaborar e propor o Plano Nacional de Desenvolvimento Rural Sustentável (PNDRS), que tem por princípios: 1) promover o acesso a terra; 2) fortalecer a agricultura familiar; 3 ) diversificar a economia do setor rural (LEITE et al, 2008).

Já, no ano de 2003, o CNDRS sofre nova reformulação, passando a se chamar Conselho Nacional de Desenvolvimento Rural Sustentável (CONDRAF), órgão colegiado integrante da estrutura básica do MDA, que tem por finalidade propor diretrizes para a formulação e a implementação de políticas públicas ativas, constituindo-se em espaço de concertação e articulação entre os diferentes níveis de governo e as organizações da sociedade civil,

${ }^{13}$ Ressaltam-se, também, como fatos históricos que pressionaram o governo e o forçou à adoção de novas políticas territoriais, os massacres de Corumbiara, em 1995 e de Eldorado dos Carajás, em 1996. 
em prol do desenvolvimento rural sustentável, a reforma agrária e a agricultura familiar.

O CONDRAF é órgão colegiado e integra a estrutura básica do Ministério do Desenvolvimento Agrário (MDA). Foi instituído pelo Decreto Presidencial $n^{\circ} 4.854$, de 8 de outubro de 2003, como uma reestruturação do antigo Conselho Nacional de Desenvolvimento Rural Sustentável (CNDRS). Seu campo de ação gira em torno de três pilares: desenvolvimento rural sustentável; reforma agrária; e agricultura familiar. (IPEA, 2012, p. 12).

Deste modo, a escolha de execução de política de desenvolvimento territorial, realizada pelo MDA, passou a privilegiar a participação da sociedade e dos demais atores do território. A opção escolhida desta vez, após os CNDRS, levou à materialização dos Colegiados Territoriais, que têm como pressuposto serem espaços:

[...][que] oportunizam o diálogo, a negociação, a aprendizagem, a transparência e a democracia necessária à construção de um ambiente favorável à integração e ao estabelecimento de consensos, de acordos, ações e compromissos coletivos fundamentais ao processo de desenvolvimento (BRASIL, 2009: 04, grifos dos autores).

Este modelo teórico, adotado pelo MDA, à frente das políticas de desenvolvimento territoriais rurais, demonstra claramente a importância dada à participação da sociedade por parte dos últimos governos, sendo esta interpretada até como ação estratégica para o alcance dos resultados pretendidos. No entanto o que não se demonstra é o poder que estes espaços de participação têm em "domesticar" os impulsos de alas mais radicais dos movimentos sociais rurais, como é o caso do Movimento dos Trabalhadores Rurais Sem Terra (MST). Neste sentido, fica nítido que o MST, a partir dos anos 2000, levados por expectativas de melhoras no campo e inseridos em espaços de diálogos e consultas, modifica consideravelmente sua atuação, deixando de ser um "movimento de protesto e ação direta" para servir-se como um "movimento de participação institucionalizada", em que a interação com o governo e latifundiários é realizada, a partir de canais de diálogos oficialmente sancionados que são guiados por regras previamente definidas e aceitas por todos os envolvidos (ABERS et al., 2014) ${ }^{14}$.

No caso especificamente dos Colegiados Territoriais dos "Territórios da Cidadania" (política mais recente

${ }^{14}$ No presente trabalho, utilizo-me de duas das rotinas comuns de interação entre Estado e sociedade, elaboradas por Aberset al (2014), entretanto divirjo de suas considerações, no que se refere a esta interação, no caso das políticas executadas pelo Ministério do Desenvolvimento Agrário (MDA). e atualmente em execução), estes são formados por representantes das três esferas de governo e da sociedade civil. A formação dos colegiados segue recomendações de que se tenham representantes de diversas áreas, a saber: governo federal, governos estaduais, prefeituras municipais, representação dos conselhos (saúde, educação, assistência, Consad’s, cultura, meio ambiente, desenvolvimento econômico, desenvolvimento rural, fórum das mesorregiões), representação de agricultores familiares, pescadores, indígenas, quilombolas, povos e comunidades tradicionais; atores econômicos (associações comerciais, industriais, da agricultura, cooperativas, sistema S) e instituições de ensino (universidades e escolas técnicas). A gestão do programa é dividida entre três atores, conforme é apresentado na Figura 1.

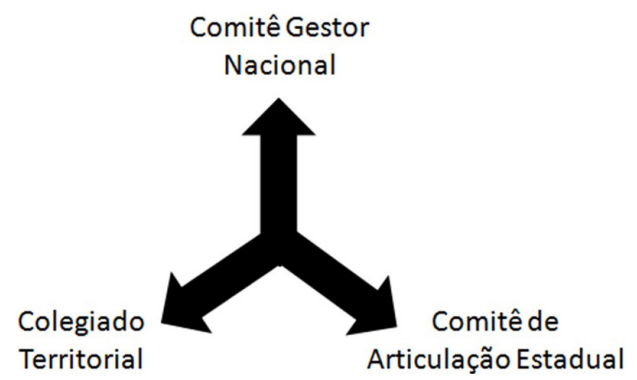

FIGURA 1 - Gestão do Programa Territórios da Cidadania Fonte: Adaptação do Ministério do Desenvolvimento Agrário e decreto de implantação do Programa Territórios da Cidadania, de 25 de fevereiro de 2008

O Comitê Gestor Nacional é composto por Secretários Executivos ou Secretários Nacionais de todos os Ministérios/Secretarias que compõem o Programa. Suas atribuições são aprovar diretrizes, adotar medidas para execução do programa, avaliá-lo, aprovar relatórios de gestão e estabelecer definição de novos territórios.

No caso do Comitê de Articulação Estadual, é composto por representantes de órgãos federais, estaduais e das prefeituras. Suas atribuições são: apoiar a organização e mobilização dos colegiados; fomentar a articulação e integração das diversas ações nos territórios; acompanhar a execução do Programa; auxiliar em sua divulgação no Estado e apresentar sugestões de novos territórios e de novas ações.

As atribuições dos Colegiados Territoriais são: dar ampla divulgação sobre as ações do PTC; identificar demandas locais para o órgão gestor, ajudando a priorizar o atendimento; promover a interação entre gestores 
públicos e conselhos setoriais; contribuir com sugestões para qualificação e integração de ações; sistematizar as contribuições para o Plano Territorial de Ações Integradas e exercer o controle social do Programa. Os colegiados também podem definir prioridades na Matriz de Ações que fortalecem os projetos estratégicos.

Neste sentido, o MDA solidifica-se, de modo evidente, à conformação e ao desenho em prol de estruturas participativas. Abramovay (2001), por exemplo, considera que a profusão de conselhos gestores foi a mais importante inovação institucional das políticas públicas brasileiras. Entretanto demais estudos (ABRAMOVAY, 2001; DELGADO E LEITE, 2011) salientam, por sua vez, que ainda há uma precariedade da participação social nestas novas organizações oriundas da submissão a poderes locais dominantes.

[...] os conselheiros podem ser mal informados, pouco representativos, indicados pelos que controlam a vida social da organização ou localidade em questão, mal preparados para o exercício de suas funções ou, o que parece tão frequente, uma mistura de cada um destes elementos. (ABRAMOVAY, 2001, p. 121)

[...] constata-se que os estudos examinados convergiram para o fato de que: a) a interação entre os diversos atores sociais nos Conselhos Municipais de Desenvolvimento Rural (CMDRs) ainda era bastante baixa; b) a definição das linhas de atuação (centradas em atividades agrícolas) e a gestão dos planos de trabalho ficavam a cargo da equipe técnica dos órgãos públicos envolvidos; c) a interação observada entre os municípios de uma determinada região dava-se mais pela competição do que pelo estabelecimento de parcerias, como também era precária as articulações entre os entes públicos das esferas municipal, estadual e federal de governo. (BRASIL, MDA/CONDRAF, 2005, apud DELGADO et al., 2011, p. 440)

As convergências sistematizadas apontavam para o fato de que os Planos Municipais de Desenvolvimento Rural (PMDRs) possuíam mais uma "lista de compras" do que propriamente um projeto de desenvolvimento, além de que a atuação dos conselhos estava primordialmente direcionada à resolução de problemas pontuais, perdendo visão estratégica de médio e longo prazo e impedindo diagnóstico mais profundo sobre os impactos da política nas economias locais (Brasil, MDA/Condraf, 2005, apud Delgado et al., 2011, p. 440).

Deste modo, pode-se observar que, nesta trajetória de quase pouco mais de 20 anos de experimentação dos conselhos participativos, na política de desenvolvimento territorial, a participação, de fato, apresenta-se como uma variável estratégica importante, todavia com pouca efetividade prática.

Além das questões acima supracitadas, o que consideramos importante ser analisado, de forma mais acurada, não é a importância ou efetividade da participação nas políticas públicas - que nos dias atuais, há inúmeros trabalhos ressaltando esta problemática -, mas, sim, o de verificar se, ao promover a participação dos movimentos sociais, estes foram ou não institucionalizados, perdendo, por sua vez, sua capacidade de pressão perante o governo e os latifundiários, levando os movimentos sociais, como o Movimento dos Trabalhadores Rurais Sem Terra (MST), a perderem sua capacidade de pressão e sua verdadeira identidade.

A ação coletiva de confronto é base dos movimentos sociais não por serem estes sempre violentos ou extremos, mas porque o principal e quase sempre o único recurso que as pessoas comuns têm contra opositores mais bem equipados ou estados poderosos. Isto não significa que os movimentos não fazem outra coisa senão confrontar: eles formam organizações, elaboram ideologias, socializam e mobilizam seus membros, e estes se engajam em autodesenvolvimento e na construção de identidades coletivas. (TARROW, 2009, p. 19).

Outro ponto que consubstancia nossas hipóteses neste paper é o fato de o Ministério da Agricultura, Pecuária e Abastecimento (MAPA) ser diametralmente oposto aos ganhos dos movimentos sociais do campo, legitimando, por sua vez, políticas públicas ligadas ao agronegócio e aos ruralistas, tendo como desenho conclusivo MDA versus MAPA, cujas principais commodities brasileiras - todas de caráter latifundiário - dão o "tom" da agenda política dos últimos governos ${ }^{15}$.

\section{CONSIDERAÇÕES FINAIS}

Neste trabalho, ressaltam-se algumas questões ideológicas, que conjuntamente com demais autores (BADIE, 1996; BUAINAIM, 1999; FERNANDES, 2000; MARTINS, 2000; MARTINS, 2004), coadunamos as quais são: Para onde caminham os movimentos sociais rurais que outrora se mantinham tão ativos? Como contribuir para a proposição de alternativas a um modelo hegemônico de caráter privatista e que advoga o consenso?

\footnotetext{
${ }^{15} \mathrm{No}$ atual momento, tal assertiva se torna ainda mais verossímil, já que com a reforma ministerial realizada pelo atual presidente Michel Temer, o MDA foi inserido no antigo MDS, que atualmente denomina-se MDSA (Ministério de Desenvolvimento Social e Agrário) enquanto o MAPA permaneceu como pasta ministerial forte e é tema estratégico na atual agenda de governo.
} 
Ao considerar todo o processo de lutas estabelecido pelos trabalhadores rurais e comparar a política outrora adotada para a esfera rural, não há dúvida de que os avanços obtidos, a partir de uma abordagem territorial, são importantes (referimo-nos, principalmente, às últimas políticas públicas territoriais realizadas após a redemocratização brasileira: Pronaf, Pronat e PTC). Todavia, além desses avanços ainda serem exíguos, para as reais necessidades do país, o atual modelo de política tem algumas questões ainda pouco explicitadas, que é o do controle político do debate público para a construção de teorias, métodos, metodologias e ideologias que visam ao controle territorial e à institucionalização dos movimentos sociais. A geografia política do debate amplo, que ainda hoje ocorre no país e em demais países periféricos revela a presença de uma "monocultura institucional" (FERNANDES, 2004), ou seja, a construção de referências teóricas correlacionadas a um desenvolvimento territorial que tem como ponto de partida e de chegada o pensamento único, que descaracteriza o conflito e o coloca como desnecessário e infrutífero. Este pensamento é uma construção ideológica que obscurantiza a forma real da questão agrária brasileira, ou seja, o da existência de um sistema em que a desigualdade é sua gênese por excelência.

Este pensamento, que flerta com uma concepção habermasiana e, por vezes, com uma concepção liberal, refere-se a um pensamento que lê a realidade sem considerar suas contradições. É um pensamento que invadiu propositalmente os espaços e organizações populares, principalmente, por meio de arranjos institucionais participativos dialógicos e consultivos inseridos em muitas das políticas públicas atuais. Esta concepção constrói um novo cenário e procura convencer os movimentos sociais e as comunidades rurais de que devem procurar o desenvolvimento, a partir do consenso, sem criar oposições. Outro argumento utilizado é o da integração - subalterna - completa das comunidades ao mercado, neste sentido, procura convencer que o desenvolvimento territorial tem o mercado como essência, desconstruindo de maneira total a possibilidade de pensamentos divergentes, projetando, por sua vez, modelos e padrões de comportamento e de visão de mundo.

É importante salientar, entretanto que a questão agrária está imersa no conceito de território, que, por sua vez, não aceita e não pode ser compreendida pela perspectiva consensual ou institucionalizada, já que o território tem como característica ser dinâmico, em que movimentos sociais, latifundiários e governo fazem parte deste grande amálgama que se resolve, a partir do diálogo, mas também ocorre a partir do conflito.

O conceito de território pode significar o espaço físico em diversas escalas: desde o espaço geográfico de uma nação, de uma região, de um estado, de uma microrregião, de um município, de um bairro, de uma rua, de uma propriedade e de partes de uma moradia. Esse é seu sentido absoluto, objetivo, concreto, material e localizado. O conceito de território pode significar também espaços sociais em suas diversas dimensões: culturais, políticas, econômicas, histórica, ou seja, as relações sociais em sua complexidade, espacialidade e temporalidade. Inclusive no plano das ideias, da construção de conhecimentos e suas diferentes leituras das realidades, do sentido e do significado, das divergências e convergências, do diálogo e do conflito. Esse é seu sentido relacional, subjetivo, abstrato, representável e indeterminado. Portanto, temos territórios em movimento. (FERNANDES, 2004, p. 41).

Dessa forma, o Movimento Rural dos Trabalhadores sem Terra (MST), que outrora foi um importante movimento impulsionador da agenda política para a esfera agrária, precisa retomar suas ações de contestação quanto às ações estatais, abandonando o comportamento adotado, a partir da gestão do expresidente Luis Inácio Lula da Silva, que levou à perda de seu protagonismo, principalmente, se comparado com suas ações na década de 1990. Sendo assim, é necessário que o MST e movimentos como a CONTAG e outros estabeleçam uma postura combativa e prospectiva, em relação aos interesses particularistas dos latifundiários, para evitarmos o "entorpecimento" da importante questão agrária brasileira, tornando os movimentos sociais players importantes para o desenho e avanço das políticas agrárias do país.

\section{REFERÊNCIAS}

ABERS, R.; SERAFIM, L.; TATAGIBA, L. Repertórios de interação Estado-Sociedade em um Estado Heterogêneo: A experiência na era Lula. Dados Revista de Ciências Sociais, Rio de Janeiro, vol. 57, n², pp. 325-357, 2014.

ABRAMOVAY, R. Conselhos além dos limites. Estudos Avançados, vol.15, n.43, pp. 121-140, 2001.

BADIE, B. O fim dos territórios. Lisboa: Instituto Piaget, 1996. 
BALDUÍNO, D. T. Prefácio. In: STÈDILE, João Pedro; FERNANDES, Bernardo. Brava Gente. São Paulo: Fundação Perseu Abramo, 1999.

BRASIL. Orientação para a constituição e funcionamento dos colegiados territoriais. Ministério do Desenvolvimento Agrário (MDA); Departamento de gestão territorial, 2009.

BUAINAIN, A. M. Reforma Agrária por conflitos: a gestão dos conflitos de terra no Brasil. Campinas: inédito, 2004.

DELGADO, N. G.; LEITE, S. P. Políticas de Desenvolvimento Territorial no Meio Rural Brasileiro: Novas Institucionalidades e Protagonismo dos Atores. Dados - Revista de Ciências Sociais. Rio de Janeiro, vol 54, no2, p.431 a 473, 2011.

DELlA PORTA, D., RIETER, H. (Orgs.). Policing Protest: The Control os Mass Demonstrations in Contemporary Democracies. Mineápolis: University of Minnesota Press, 1997.

FERNANDES, B. M. Questão Agrária: Conflitualidade e desenvolvimento territorial. Seminários no Lincoln Institute of Landy Policy e na Harvard University. Cambridge: abril de 2004, 2004.

Editora Vozes, 2000.

A Formação do MST no Brasil. São Paulo,

IPEA. O Conselho Nacional de Desenvolvimento Rural Sustentável na Visão de seus Conselheiros. Relatório de Pesquisa. Projeto Conselhos Nacionais: perfil e atuação dos conselheiros. IPEA, 2012.

Políticas sociais: acompanhamento e análise. (jun. 2000). Brasília: IPEA, 2011.

LEITE, S. Desenvolvimento territorial: articulação de políticas e atores sociais. In: MIRANDA, C; TIBURCIO, B. (Org). Articulação de Políticas Públicas e Atores
Sociais. Brasília: IICA. Série Desenvolvimento Rural Sustentável; v.8, 2008.

MARTINS, J. S. O cativeiro da terra. São Paulo: Hucitec, 1986.

Reforma agrária: o impossível diálogo. São

Paulo: Edusp, 2000.

MARTINS, M. O Banco Mundial e a terra: ofensiva e resistência na América Latina, África e Ásia. São Paulo: Viramundo, 2004.

NAVARRO, Z. Desenvolvimento rural no Brasil: Os limites do passado e os caminhos do futuro", Revista Estudos Avançados, 16 (44): 83100, 2001.

OLIVEIRA, A. U. AAgricultura Camponesa no Brasil. São Paulo: Contexto, 1991.

Barbárie e Modernidade: as transformações no campo brasileiro e o agronegócio no Brasil. In: Revista Terra Livre, São Paulo: AGB, ano 19. n. 21, 2003, p. $113-156$.

SAMPAIO, P. A.. Proposta do Plano Nacional da Reforma Agrária. Brasília, (não publicado), 2003.

STÈDILE, J. P.; GORGEN, F. S. A luta pela terra no Brasil. São Paulo: Scritta, 1993.

STÉDILE, J. P. A Questão Agrária no Brasil: o Debate Tradicional: 1500-1960. São Paulo. Editora Expressão Popular: 2005a.

. A Questão Agrária no Brasil: o Debate na Esquerda: 1960-1980. São Paulo. Expressão Popular: $2005 b$.

TARROW, S. O poder em movimento: Movimentos sociais e confronto político. Petrópolis: Editora Vozes, 2009. 